\title{
AN OBSERVATION ABOUT NORMALOID OPERATORS
}

\author{
JOR-TING CHAN AND KONG CHAN
}

Abstract. Let $H$ be a complex Hilbert space and $B(H)$ the Banach space of all bounded linear operators on $H$. For any $A \in B(H)$, let $w(A)$ denote the numerical radius of $A$. Then $A$ is normaloid if $w(A)=\|A\|$. In this note, we show that $A$ is normaloid if there is a sequence of unit vectors $\left(x_{n}\right)$ such that $\lim _{n \rightarrow \infty}\left\|A x_{n}\right\|=\|A\|$ and $\lim _{n \rightarrow \infty}\left|\left\langle A x_{n}, x_{n}\right\rangle\right|=w(A)$ simultaneously. The result is then used to study the Davis-Wielandt radius.

Mathematics subject classification (2010): 47A12, 47B20.

Keywords and phrases: Numerical range, normaloid, Davis-Wielandt shell.

\section{REFERENCES}

[1] M. BarraA And M. Boumazgour, Inner derivations and norm equality, Proc. Amer. Math. Soc. 130, (2002), 471-476.

[2] J. T. CHAN AND K. ChAN, Two distance preservers of generalized numerical radii, Linear Multilinear Algebra 62 (2014), 674-682.

[3] C. DAVIS, The shell of a Hilbert-space operator, Acta Sci. Math. (Szeged) 29 (1968) 69-86.

[4] M. GoldBerg AND G. ZWAS, On matrices having equal spectral radius and spectral norm, Linear Algebra Appl. 8 (1974), 427-434.

[5] P. R. Halmos, A Hilbert space problem book, 2nd ed., Springer-Verlag, New York, 1982.

[6] C. K. LI, Y. T. Poon, Spectrum, numerical range and Davis-Wielandt shell of a normal opearator, Glasgow Math. J. 51 (2009) 91-100.

[7] C. K. LI, Y. T. Poon, Davis-Wielandt shells of normal operators, Acta Sci. Math. (Szeged) 75 (2009), 289-297.

[8] C. K. Li, Y. T. Poon, N. S. Sze, Davis-Wielandt shells of operators, Oper. Matrices 2 (2008), $341-355$.

[9] L. Z. Gevorgyan, Characterization of spectraloid and normaloid operators, Dokl. Nats. Akad. Nauk Armen. 113 (2013), 231-239.

[10] A. SEDDIK, On the injective norm of $\sum_{i=1}^{n} A_{i} \otimes B_{i}$ and characterization of normaloid operators, Oper. Matrices. 2 (2008), 67-77.

[11] J. G. STAMPFl, The norm of a derivation, Pacific J. Math. 33 (1970), 737-747.

[12] L. S. WANG AND H. XUE, Norm equality and maximal numerical range, (Chinese) J. Ningxia Univ. Nat. Sci. Ed. 27 (2006), 193-196. 